\title{
ARGUEDAS: REFLEXIONES Y APROXIMACIONES
}

\author{
POR \\ NOE JITRIK \\ El Colegio de México
}

Después de haber escuchado al profesor Murra y a Angel Rama me siento, junto a la figura de Arguedas, un poco como el argentino aquel del Departamento de Estado evocado por Murra, porque en realidad mi relación con Arguedas es muy episódica y marginal. Cuando Julio Ortega me propuso intervenir en este simposio, me di cuenta de dos cosas: primera, de que no conocía a Arguedas; segunda, de que no había yo logrado elaborar la imagen que había tenido cuando leí Los ríos profundos, en el año sesenta aproximadamente. Cuando leí Los ríos profundos sentí algunas cosas que me prometí desarrollar y que nunca hice; por tanto, en una suerte de desafío a mi omnipotencia que me hizo indirectamente Julio, me dije que quizá era el momento de desarrollar esa idea. ¿Habrá llegado? Voy ahora simplemente a entregarles algunas reflexiones que, muy superficiales, hice leyendo algunas cosas más de Arguedas; pero aquella imagen perdura, no renuncio a transmitírselas.

Aquella imagen de Los ríos profundos consiste en lo que yo llamaría el toque, o sea, la imagen del niño tocando los muros del Cuzco; es una imagen casi bíblica, de inminencia bíblica: debería salir agua de esos muros porque el niño, de alguna manera, está investido de poder; pero no sale agua, sale angustia, que es la que se desarrolla permanentemente en Los ríos profundos. El relato presenta y desarrolla esa relación entre la inminencia de un milagro que tiene fuertes raíces en la historia, en la realidad psicológica, pre-psicológica, casi fetal, de pérdida, etc., y una angustia que se inscribe desde la situación individual en el mundo en su totalidad, porque no hay nada que el niño sienta que no tenga una relación con el mundo. Esta lectura me trans- 
mitió también la imagen de una solemnidad, como que yo estaba leyendo algo profundamente serio, solemne en el sentido de los ritos, que no tienen la formulación de tales, que no se realizan en los atrios o en los templos, pero, sin embargo, apelan a una pluralidad de instancias. Curiosamente, lo que también me queda de esa primera imagen es el trompo, como un objeto que tenía o debía tener alguna significación. Ahora Angel Rama, al hablar de la musicalidad y de la oralidad, establece, creo, un puente con el trompo, al que se podría ver como objeto concentrador, diría yo.

Ahora, en los comentarios que voy a hacer, seguramente algunas palabras de esta jerga, como concentrador, que es un anticipo, van a aparecer, por lo cual les pido perdón por adelantado.

En estas reflexiones, superficiales, que voy a presentar he tratado de centrarme en lo que a mi gusto serían algunos puntos de partida para considerar el aspecto literario, si cabe, de la obra de Arguedas. E1 inicial es algo muy obvio; se me ocurre que en la superficie, o aparentemente, de todas las narraciones de Arguedas, de todas sin excepción, el elemento o el eje central es el personaje, que parece ser sin duda lo más importante; todo gira a su alrededor; ahora bien: la importancia no reside en el hecho, por ejemplo, de que los narradores son al mismo tiempo personajes, a veces pacientes, a veces activos, sino en que, además, también aparentemente, o de manera superficial en el sentido de lo que se ve inmediatamente, hay una clasificación muy refinada de personajes mediante el clásico sistema de las oposiciones, lo más obvio también: a los serranos se oponen los costeños, a los blancos se oponen los indios, los mestizos ocupan un lugar intermedio, etc.; en el plano social, los gamonales aparecen frente a los comuneros, los señores feudales a los propietarios pobres y a los obreros, es decir, la gama de la vida social aparece personificada.

Ahora bien: yo sospecho que en todas las narraciones de este tipo, y que constituyen el mayor caudal, casi todo el acervo narrativo, el personaje predomina; pero, en mi opinión, es sólo un elemento, no es todo en la narración. Justamente si se toma este elemento como único y el central, se toma una parte por el todo, lo cual, seguramente, ha llevado a un tipo de lecturas que no son nada más, pienso, que un comentario sobre las acciones que los personajes llevan a cabo, o bien sobre la psicología de los personajes, o sobre los enfrentamientos que realizan entre sí; en cambio, aun aceptando la centralidad del elemento «personaje», no creo haber leído nada que lleve a una tipología, en el sentido estructuralista de la palabra, lo que implicaría un nivel superior que, por el momento, está ahogado por el interminable comentario sobre en- 
frentamientos de sujetos; en Todas las sangres, por ejemplo, tenemos a los dos hermanos, dos caracteres opuestos, lo que da lugar a una cantidad de reflexiones sobre el punto que confluyen, por último, en una conocida actitud frente a la literatura, o sea, considerar que los personajes representan realidades. Efectivamente, hay de donde agarrarse para hacer todo esto, pero me parece que se trata de una trampa para la lectura y para la crítica de una obra como la de Arguedas. En consecuencia, en función de este comentario excluyente sobre los personajes, es muy natural que algunos críticos los encuentren contradictorios, confusos, ambiguos. También hay de donde agarrarse para hacer todo esto, pero me parece que se trata de una trampa para la lectura y para la crítica de una obra como la de Arguedas. En consecuencia, en función de este comentario excluyente sobre los personajes, es muy natural que algunos críticos los encuentren contradictorios, confusos, ambiguos. También hay de donde agarrarse para ello si uno piensa en un personaje como el Bruno Aragón de Peralta de Todas las sangres: no se sabe por qué de pronto es un fanático medieval, y de pronto es un dostoievskiano, y de pronto tiene un amor purísimo por la mestiza, etc. Yo creo que, efectivamente, los personajes pueden ser incongruentes, confusos y ambiguos, todo lo cual me parece, en este caso, de escasísima importancia, tanto que no constituye ni siquiera el principio de una crítica. Lo que, en cambio, se podría elaborar es que la reconocida incongruencia en el comportamiento es a veces tan marcada que se rompe un sagrado principio del realismo, el de la causalidad, que, como se sabe, es el principio sagrado de la retórica realista. Ahora bien, para perdonarle la vida al escritor que ha construido personajes incongruentes, ambiguos y confusos se habla de «complejidad del alma humana». Si el odio y el amor tienen una frontera poco establecida y poco clara, entonces cada vez que se sospecha que hay un personaje mal trazado y no se quiere decirlo, por un natural respeto a la obra, se habla de la complejidad del alma humana; creo que todos cuidamos bastante esa frontera, no la transgredimos con dispendiosidad anímica precisamente para evitar riesgos; por todo ello, todas éstas son formas de considerar una obra importante y crucial de la literatura latinoamericana desde perspectivas poco rigurosas. Desde luego, esto no significa que la mía vaya a ser rigurosa, y mi debilidad consiste en que estoy permanentemente oscilando en un juego de categorías que son una selva en la que tengo que orientarme para poder de alguna manera hablar, a pesar de o porque pienso que otras voces han simplificado el fenómeno.

Tengo también la impresión de que si es cierto que la incongruencia de los personajes rompe el causalismo, la ruptura del causalismo en esos 
comportamientos compromete otra causalidad: la causalidad de las acciones; es decir, que habría una categoría, los personajes y sus comportamientos, con sus reglas de causalidad o de congruencia, y también otra, las acciones en las que intervienen más elementos; no dependen sólo del comportamiento de los personajes, sino que, hasta cierto punto, son resultado de una confluencia de factores; ahora bien, si se rompe la causalidad en las acciones, el resultado es que se produce una fractura de la representación, la cual, a su vez, es un requisito de cierto tipo de literatura. Viendo las cosas de otro modo, entiendo que muchos de los trabajos existentes sobre Arguedas establecen una relación muy directa entre la estructura verbal que se nos presenta, el texto que tenemos que leer y una realidad representada. Naturalmente, hay en esta proposición muchas cosas como para desarrollarla, pero el problema no es ése, al menos para mí; lo que en este instante me importa de Arguedas no es lo que ya sabemos acerca de la realidad peruana, sino el texto que Arguedas realiza a partir de la realidad peruana, en y contra la realidad peruana; no me interesa, en suma, el problema de la representación con los conexos de la exactitud o la fidelidad. $Y$ bien, yo creo que, a pesar de que hay fracturas e incongruencias en los personajes y ruptura en la causalidad de las acciones, mayor en algunos textos que en otros (como, por ejemplo, en Todas las sangres, texto que, según he leído, Arguedas lo sentía como uno de sus trabajos principales), que producen una cierta discontinuidad desde una perspectiva realista, la discontinuidad no impide que de estos textos fluya, y no puedo más que usar una imagen, un hálito poderoso, algo que invade el ámbito del lector y lo compromete al lector, comprometiendo también la lectura. Ese reconocimiento me quita problemas en relación con las clasificaciones tales como «indigenismo», «idealismo» y todo ese tipo de etiquetas; cuando uno se acerca a un texto que ya se sabe que es "indianista», pero que le es presentado como «indigenista», hace jugar una actitud casi etnográfica, como si se pusiera frente a un documento de determinado tipo, ya codificado. Desde una perspectiva de lectura, el problema queda neutralizado: yo, como lector, soy tomado por un impulso de lectura que fluye de los textos, lo que sitúa la discontinuidad en otro plano: ya no aparecería como un defecto del realismo, sino, justamente, presentaría otra instancia, sería un indicio de la instancia.

$\mathrm{Si}$, por otro lado, para salir de este problema de la ruptura de la congruencia, y como proponiendo una clave, se dijera que se trata, como se dice modernamente, de «novela del lenguaje», se apelaría igualmente a una fórmula para salir del compromiso; en otras palabras: todo lo que no se entiende como novela realista podría ser novela del lenguaje, fór- 
mula que sería, de este modo, sustitutiva de algo que no se entiende y además de una obviedad que no necesita mayores desarrollos; desde luego es una «novela del lenguaje» no sólo porque es del lenguaje, sino porque tendría como respaldo un conflicto bastante evidente de bilingüismo además de la función - a través del empleo-, que puede cumplir el quechua en tanto lengua protectora de la canción, de la oralidad de la poesía primitiva, como lo ha señalado Angel Rama; el conflicto de bilingüismo en estos textos se plantea como problema trascendente no sólo como una relación entre dos niveles del lenguaje en un texto, sino también como un problema extratextual. Considerar entonces simplemente que es una novela del lenguaje sería negarse a la necesidad de un acceso más abarcativo a este texto, según el cual, y para empezar, éstas serían para mí las condiciones iniciales.

Se debería reconocer, por de pronto y en primer lugar, que el problema de la narración misma, o, para usar una expresión un poco más técnica, el problema de la enunciación narrativa, se da en Arguedas como conflicto de escritura, en la medida en que no está de ninguna manera separado de una experiencia de identidad: en la enunciación (yo, él, nosotros) hay un trasfondo de experiencia de identidad. Un indicio de ello podría ser el hecho de que muchos personajes son niños que, como personajes, incluyen necesariamente la cuestión de la identidad: al mismo tiempo que el niño relata se va construyendo. Esta cuestión de la identidad en la función narrativa tiene un momento crítico por cuanto liga, naturalmente, la narración con ciertas actitudes o inflexiones narrativas y con ciertos temas y personajes recurrentes; lo cual es fácilmente verificable en todas las novelas de Arguedas; si las superponemos idealmente, por medio de una computadora, por ejemplo, veríamos que hay muchos temas y personajes recurrentes y funciones literarias o literario-ideológicas, si ustedes quieren, también recurrentes.

Ese es el primer nivel de ingreso; en el segundo nivel se debería reconocer que el conflicto exterior, extratextual, también está presente, pero no sólo como exposición de problemas, sino determinando la escritura misma, interviniendo en ella. Claro, es fácil decir, en este sentido, que Arguedas escribe sobre los nuevos obreros de la harina del pescado; ésta sería la imagen tradicional, es decir, que representa conflictos; el problema es que estas nuevas realidades estructurales de una sociedad como la peruana también inciden en la estructuración de la escritura.

E1 tercer nivel, pienso yo, para entrar en esta textualidad de una manera más abarcativa, exigiría el reconocimiento de que en el lenguaje del texto de Arguedas pasa algo; desde luego se admite que el texto es 
un hecho del lenguaje, es decir, que hay un cierto drama, digamos, que tiene como escenario también las palabras; y retomo algunas de las cosas que dijo Angel Rama, con el que no me sorprende coincidir en este punto, porque permanentemente coincidimos en ciertos puntos, a pesar de que no nos vemos durante mucho tiempo. Dadas entonces estas tres posibilidades, ¿cómo encontrar un acceso a la textualidad? Por cierto, yo no tengo nada organizado ni sistemático para este acceso (tampoco es el momento de hacerlo en un simposio que fundamentalmente es un homenaje a un gran escritor y a una personalidad representativa de América Latina; entrar con propuestas excesivamente sistemáticas, que naturalmente son muy aburridas, a menos que se tenga tiempo para desarrollarlas; nótese que, a pesar de que hablo de la necesidad de algo organizado y sistemático, no lo presento, por lo cual también yo me instalo en una serie sucesiva de paradojas); reconozco, en cambio, que en la lectura que hice antaño y en la actualidad tendía a ser sensible a las apelaciones sentimentales, más quizá que a otras sugerencias que también salen del texto; el mundo sentimental me afectó muchísimo, lo cual también me bloqueó para otro tipo de nivel que me permitiera el deseado ingreso más abarcativo, que creo que, no obstante, hay que hacer. El trabajo del crítico es bastante complicado: es exigido por algún núcleo del texto; pero, al mismo tiempo, tiene que ser coherente consigo mismo para poder obtener frutos de su trabajo; hay, por tanto, un conflicto que tiene que ser de alguna manera, en un punto determinado, resuelto. Yo declaro que, a pesar de que entiendo que se necesita un acceso más abarcativo para el cual el comentario sobre el comportamiento de los personajes es insuficiente, reconozco que lo que más me tocó, lo que más me implicó, fue el aspecto sentimental de los textos de Arguedas, y ese reconocimiento me produce cierto bloqueo. Por lo tanto, voy a proponer sólo algunas líneas de pensamiento, muy desordenadas, que pueden dar alguna respuesta a estas tres categorías, o tres necesidades, o tres planos que creo que se deberían tener en cuenta.

1) Yo creo que los relatos de Arguedas están construidos según un modelo proporcionado, indudablemente, por la realidad; por eso podrían quizá estudiarse según cierta lógica de acciones, no muy alejada de la lógica de las acciones de la realidad misma (llegada, recepción, amistad, conflicto, desenlace, reflexión). Pero en virtud de que otras instancias -otros cortes propiamente escriturarios- se hacen entrar, la obediencia o el seguimiento a ese modelo de la realidad no implica de ninguna manera una actitud de representación ni de reflejo de lo real; por lo cual, y aunque parezca paradójico, sería inconveniente hablar 
de esta obra como de una obra realista. Dicho de otro modo: el modelo de la realidad posee una capacidad o un poder organizativo de la estructura narrativa, mientras que el realismo como ideología supone una intención de reproducir los contenidos o los elementos de la realidad. Esta breve distinción metodológica me sirve para avanzar un poco más en la comprensión del problema. En El sexto aparece este esquema con claridad: ingreso a un sitio, presentación, exposición, conflicto, resolución del conflicto, partida. Pero esto no es prueba de realismo, puesto que en la escritura entran otros niveles que inciden sobre el esquema. Sin contar con que el esquema mismo es funcional y operativo; el realismo, en cambio, implicaría una intención deliberada de reproducir -y creer que se lo logra- - los elementos contenidos en la realidad. Pienso que la obra de Arguedas cae fuera de una consideración semejante.

2) El sentimentalismo permanente tiene, sin duda, una fuente real, que es la idiosincrasia indígena; aquí los etnólogos podrán determinar con más claridad si existe tal idiosincrasia indígena; desde luego, en función de su presencia tan desbordante, filia la obra, de acuerdo con las estructuraciones de la historia de la literatura, más o menos fundadas, y que se llaman «escuelas literarias», «movimientos», «tendencias»; en este sentido, Arguedas sería más o menos romántico, lo cual es el aspecto menos interesante y más fácil. Ahora bien, la manifestación de los sentimientos se hace notoriamente a través del llanto, el cual sirve de elemento fusionante y establece, siempre o casi siempre, una vinculación con ciertas categorías mágicas, que dan fundamento a una especie de animismo: las montañas se quejan, las montañas amenazan; este animismo daría lugar a una especie de "realismo mágico», si ustedes quieren, que no es exactamente el otro realismo más o menos socorrido, y que podría ser muy propio del mundo indígena, al menos como lo quiere Asturias.

3) El nacionalismo, que aparecería en la obra de Arguedas, no lo haría de ninguna manera como color local ni como indigenismo, sino utilizando una imagen, una metáfora, yo diría que como un enigma valorizado; se trataría de saber qué es la nación y, por tanto, qué es el nacionalismo; desde luego es un enigma filosófico, no práctico, en la medida en que, evidentemente, esta obra tiende a situarse muy concretamente en el plano del conflicto y no de la definición: conflicto de una nación con otras naciones y en su propio interior en relación con su identidad, con sus desarrollos y con su futuro. Pero como en la pro- 
puesta hay una interferencia de elementos disímiles, que no logran integrarse, el nacionalismo, que está siempre presente, aparecería para mi gusto como un enigma valorizado, es decir, como un enigma de una importancia capital, volcado hacia un pasado que necesariamente es traumático. Entre este pasado traumático y un futuro sombrío hay un cruce que da lugar a las tramas, es decir, que estas dos perspectivas crean la escena necesaria para que se produzcan los dramas. Ciertamente, no estaría alejado de esta estructuración en torno al nacionalismo la propia historia personal, el pasado traumático, infantil, de pérdidas, y un futuro sombrío, como el propio suicidio de Arguedas lo pondrá en evidencia, suicidio no imprevisible, sino muy preparado. Habría allí, por tanto, una suerte de mezcla de niveles o de planos, de una profundidad muy grande.

4) Todas las sangres, según puede leerse, tiene como telón de fondo dos instancias políticas: las promesas electorales de Belaúnde Terry y las acciones de Hugo Blanco. Al decir eso se quiere insinuar que hay un horizonte ideológico-político detrás de cada novela, además de la representación de la realidad. Probablemente la idea de la compañía minera, que parece nacional, pero que tiene relaciones internacionales, parecía propio de la época de Belaúnde; entraría la historia de la época de Belaúnde por ese lado, es decir, por la presentación de una determinada estructura. Esto sugiere otros problemas un poco más amplios que el de la representación, aun a través de formas como la de la compañía minera; por ejemplo, qué papel organizador había desempeñado en el pensamiento de Arguedas y en la exposición y estructuración de los conflictos la revolución cubana. En la medida en que se toma sólo lo que los personajes dicen sobre comunistas y apristas, por ejemplo, y sobre la independencia política, notoriamente en $E l$ sexto, frases que también aparecen en El zorro de arriba y el zorro de abajo, se deja de lado lo que una suma de situaciones y un lenguaje ideológico puede haber engendrado. Quisiera no ser demasiado oscuro en este punto, aunque el que esta observación sea apenas un apunte, una intuición, necesariamente produzca esta impresión; por ejemplo, Antonio Cornejo Polar destaca, muy agudamente, en $E l$ sexto, sobre el final, que la guitarra que no se termina de construir y que las canciones que vuelven a ser, las de esos monstruosos homosexuales que están en los pisos de abajo, implica una falta de salida; efectivamente, pareciera que no hay salida, lo que no me parece que sea simplemente el estado de ánimo que corresponde a la época política que se estaba viviendo en el Perú en la época en que se escribe $E l$ sexto, o sea, a la dictadura de Odría; 
no creo que sea eso lo que hay que buscar. Quizá más importante, para dar una idea de lo que quiero decir, sea en El sexto la idea de que ligar los tres pisos de la cárcel no es sólo posible, sino que contiene un elemento de ruptura, según el cual la tensión dramática de El sexto no estaría tanto en el encuentro entre distinto tipo de personajes como en la idea de la comunicación entre los pisos. Se sugeriría entonces que es posible romper la estamentación y concebir una acción desde el tercer piso sobre el primero, lo que generaría el movimiento dramático, crearía las situaciones, produciría los efectos; por ahí, creo, entra en el análisis y se hace presente cierta pulsión de la realidad, encarnada, quizá, en ciertas posibilidades de pensamiento que podrían darse sobre el final de la guerra, época en la que se escribe $E l$ sexto. Esto sería algo del material que constituye la discusión de Arguedas con Cortázar y Fuentes; explicaría sus sarcasmos sobre la construcción de Rayuela o de las obras posteriores de Cortázar, e implicaría, indirectamente, implícitamente, un ataque al estructuralismo, que estaría detrás de esa obra como corte ideológico que modela toda una escritura y una actitud literarias. Arguedas no reivindicaría otra para sí, pero en su textualidad aparecerían ciertos elementos de la realidad como determinando ciertas estructuras.

5) Al respecto, quiero añadir que el sentido de muchas situaciones -y aquí voy a coincidir expresamente con algo que Angel Rama desarrolló muy agudamente- se ilumina por medio de poemas quechuas y no por medio de desenlaces de tipo naturalista; las resoluciones, en un sentido clásico, efectivamente son pobres, pero, en cambio, los poemas que desanudan una situación son ricos; a la vez, los poemas son quechuas, pero aparecen traducidos, lo que supone un conflicto en la medida en que indica un límite en el universo de lecturas; la musicalidad implicada es la original quechua, pero se los presenta traducidos; la consecuencia es que, frente a una pérdida del referente oral, hay un rescate del código escrito, y en él, de una búsqueda, o sea, de una investigación permanente que afectaría la escritura y que corroboraría lo que se ha señalado en el primer punto, a saber: otra limitación al realismo, en virtud de la existencia de un destinatario: el lector es castellano. Como es natural, tenerlo en cuenta implica una correlativa renuncia a un lector todavía inexistente en quechua. Pero eso no significa una renuncia al elemento, que sigue siendo quechua y cuya valorización justifica que sea traducido; ahí hay algo que merece una investigación, pero no en un sentido académico, sino en el sentido de los conflictos principales que modelan y recorren, como ríos profundos, la obra de 
Arguedas. Complementariamente yo diría que este aspecto, de naturaleza linguística, con el matiz de la traducción y de acotación, genera un efecto estilístico-estético que yo podría designar como «sacro-indo-hispano». La imagen (anoté aquí del capítulo II al V de Yawar Fiesta) con la que podría comparar esa escritura es, por ejemplo, la que suscitan esas iglesias que hay en el estado de Oaxaca, México, construidas según un modelo de catedral gótica, pero por artesanos indígenas y con un lenguaje de imágenes que es sacro, indo, hispano; en la escritura está vivido como pulsión estilística, razón por la cual genera personajes. Vistas las cosas así, estamos situados en el otro lado de la cuestión; los personajes no son representados, sino que surgen de una pulsión estilística; el Bruno Aragón de Todas las sangres, por ejemplo, es uno de los resultados más notorios de esta pulsión y, por tanto, resulta necesario para esta estética de origen linguiístico.

6) La descripción, necesidad y virtud del relato tradicional, tiende en los textos de Arguedas a la preparación de acciones, o de enfrentamientos parciales, que culminan en levantamientos colectivos; es una constante, lo que implicaría una suerte de estructura épica, en la cual los conflictos estallan, o no, como en otro tipo de relato, de pretensión analítica, en los que la descripción de conflictos tiende a explicarlos y valorarlos.

Tiendo a pensar que esto está ligado a otro problema que también evocó Angel Rama, y que me gustaría comentar: el pasaje de lo individual a lo colectivo; la estructura épica, evidente y realizada, no sólo vale porque es épica o porque canaliza y expresa ciertos conflictos, sino porque tiene consecuencias en la realización de los personajes. Quedándonos en este plano, diría que, como en toda articulación épica, la literatura pretende de alguna manera realizar también una acción sobre el exterior; el valor de la épica, lo sabemos, consiste en que no sólo recoge hechos que pueden haber ocurrido, para glorificarlos y cantarlos, sino que pretende constituirse en modelo de lo real, pretende señalar una norma para la sociedad a partir de la lectura; y esto también está implicado en la obra de Arguedas.

7) Lo político, que entra también en su obra, me parece muy original. Por de pronto, lo representado, aun elementalmente, contiene todos los términos que llevarían a planteamientos políticos: la cuestión de la explotación, la opresión, las masas, los individuos, etc., todo lo cual configuraría un primer plano; el segundo estaría encadenado en los discursos políticos conocidos: apristas, comunistas, independientes, 
social-cristianos, místicos, etc., discursos que entran, ya sea en colisión, ya episódicamente, en contacto, en lo cual hay un tributo en la relación con la realidad externa.

Contrariamente a la opinión de algunos, uno de los libros de Arguedas que más me interesó fue $E l$ sexto. Sentí que era como una caldera a presión, pero no sólo por lo dramático y lo espectacular de las escenas, sino también por la presencia de este tipo de conflictos. Que los apristas y los comunistas tengan de pronto en el texto zonas de inclusión de sus discursos tiene que estar corroborado por el afuera y apoyado en el afuera, tiene que ser pensado como posible desde una estructura real, mito o pérdida de un frente popular; la idea de un frente popular, como ustedes saben, es una articulación datada históricamente, surge en un momento determinado, pero no es solamente un artefacto político, es una manera de pensar la política y, por tanto, es una manera de organizar la vida; consecuentemente, la imaginación y, finalmente, discursos diferentes. Este punto es el que me interesa destacar, porque -y eso es lo que en El sexto, a mí personalmente, en ese momento, quizá por necesidades coyunturales mías, me importa más- se reintroduce la cuestión del sujeto en la política. Pero no se trata del tema sartreano, según el cual un sujeto que está fuera del aprismo y del comunismo, como estructuras orgánicas, quiere hacer algo porque siente que está implicado con el drama de la realidad, si bien hay algo de eso; de todos modos, más bien creo que el conflicto que se presenta allí es el de un sujeto como «espacio» del drama político, como el lugar donde el drama político se lleva a cabo. No sólo como un campo oral de opciones - «yo adhiero al aprismo, yo adhiero al comunismo», que sería la manera de manifestarse que tienen en $E l$ sexto los apristas y los comunistas-, sino también porque hay un personaje que tiene una concepción diferente de lo que es el espacio político, y, frente a la otra, se produce el conflicto.

Para el personaje es un espacio subjetivo; la subjetividad sería algo así como el espacio donde se cruzan las líneas de la realidad y donde la política se gesta o se forma. Yo diría que este sujeto está pensado a la manera de un marxismo posalthusseriano; en eso reside la originalidad del planteo, ya que, por otra parte, como bien lo dijo el profesor Murra, Arguedas se consideraba débil teóricamente; es muy probable que en la época en que hacía esa declaración no conociera las polémicas marxistas en general y tampoco éstas, a las que estoy aludiendo, que son exteriores a su campo de intereses y a su vida misma. Esta consideración probaría, una vez más, que un texto, porque tiene estas y otras implicaciones, hace algo más que representar el mundo en el que se produce; por 
ejemplo, tiende brazos hacia maneras de pensar del mundo que pueden ser formuladas mediante otros discursos mucho después. Retomando, yo diría que se trata de una especie de marxismo posalthusseriano en el cual el sujeto suelto, independiente, introduce su campo de pulsiones en la objetividad, pero formando parte del campo de la objetividad y determinado por el campo, aunque no sometido, intentando entender el campo de la objetividad y deseando, desde la memoria, las vísceras y la consciencia, modificarlo.

Esto se liga, quizá, a mi imagen inicial de Los ríos profundos, el dedo apoyado en el muro: se desea míticamente que salga agua, pero sólo sale angustia; el deseo predomina, aunque no se vea satisfecho, y recorre la obra de Arguedas como uno de esos ríos profundos, que sería algo más que los ríos geográficos. Pero ese deseo no es metafísico, es un deseo que puede ser visto desde un corte teórico; deseo del sujeto deseante por así decir, que construye el espacio político y se va construyendo a sí mismo. Entonces, si hablamos de lo político en El sexto, pero en todas partes tenemos que señalar que no es un en-sí, sino que reintroduce el tema del deseo y de su historia, y su arranque, como se puede verificar en la obra de Arguedas muy claramente, es traumático: el deseo nace en la obra de Arguedas como algo que se interrumpe de entrada y que se persigue eternamente; ésta es la infancia condicionada, sin imagen materna, con imagen paterna en riesgo, con un asedio cultural, con conflictos, etc.

8) Por último hay una presencia de objetos significantes: el trompo, la guitarra, el zumbayllu, etc.; me parece que funcionan como objetos concentradores en los que se depositan muchas líneas; así, el protagonista que los maneja o que aspira a manejarlos, porque también son objetos de deseo, se encuentra siempre con otro personaje, en torno a dichos objetos, que posee numerosos atributos ideológicos: es más prestigioso, lo maneja mejor, tiene cierta sabiduría de construir una guitarra y tiene, que es lo que importa, un ofrecimiento, que establece una conexión, crea un vínculo. En el caso del trompo ocurre lo mismo, y también con la piedra que se arroja a través del río en uno de los cuentos, y para lo cual hay una habilidad especial; ambos objetos investidos suponen una concentración, al menos de personajes, uno de los cuales aparece como aspirante y el otro como socialmente consagrado.

Por otra parte, en un segundo nivel, la descripción de los objetos se recarga de un sentimentalismo muy fuerte: cuando esos personajes se encuentran en el objeto concentrador se producen acciones de carácter más general y que abarcan otros planos. Además, si bien son objetos 
que pertenecen a cierta tradición, no aparecen para reivindicar la tradición. De todos modos, un conocimiento antropológico y etnográfico se hace presente en ellos, como conocimiento borrado, no sólo porque, como Angel Rama y el profesor Murra lo señalaron, Arguedas no tenía necesidad de exhibir sus conocimientos, sino porque está por detrás como historia, obedeciendo al mecanismo de la escritura, que transforma, produce y presenta lo que, al mismo tiempo, está ausentando. Con esos objetos y su tratamiento se quiere hacer progresar la narración y crear un pasaje, a través del objeto concentrador, de lo lírico a lo épico, o sea, del llanto individual al grito colectivo. 
